\title{
The Potential Interaction of Ethionamide-Thyroid Hormone Receptor Induces Hypothyroidism
}

\author{
Ronny Lesmana ${ }^{1,2, *}$, Firyali Rahmani Shidqi ${ }^{3}$, Hanna Goenawan ${ }^{1,2}$, Iwan Setiawan ${ }^{1,2}$, Marisca Evalina \\ Gondokesumo ${ }^{4}$, Farida Suhud ${ }^{4}$, Nasrul Wathoni ${ }^{5}$
}

Ronny Lesmana ${ }^{1,2, *}$, Firyali

Rahmani Shidqi ${ }^{3}$, Hanna

Goenawan $^{1,2}$, Iwan Setiawan ${ }^{1,2}$,

Marisca Evalina Gondokesumo ${ }^{4}$,

Farida Suhud ${ }^{4}$, Nasrul Wathoni ${ }^{5}$

'Department of Biomedical Sciences, Faculty of Medicine, Universitas Padjadjaran,

Jatinangor 45363, INDONESIA.

${ }^{2}$ Physiology Molecular Laboratory, Biological Activity Division, Central Laboratory,

Universitas Padjadjaran, Jatinangor 45363, INDONESIA.

${ }^{3}$ Undergraduate Program of Medical Doctor Faculty of Medicine, Universitas Padjadjaran, Jatinangor 45363, INDONESIA.

${ }^{4}$ Faculty of Pharmacy, University of Surabaya Surabaya 60294, INDONESIA.

${ }^{5}$ Department of Pharmaceutics and Pharmaceutical Technology, Faculty of Pharmacy, Universitas Padjadjaran Jatinangor 45363, INDONESIA.

\section{Correspondence}

\section{Ronny Lesmana}

Department of Biomedical Sciences Faculty of Medicine; Physiology Molecular Laboratory, Biological Activity Division,

Central Laboratory, Universitas Padjadjaran Jatinangor 45363, INDONESIA.

E-mail: cloencool@gmail.com

History

- Submission Date: 15-04-2021

- Review completed: 28-05-2021

- Accepted Date: 03-06-2021.

DOI : 10.5530/pj.2021.13.150

Article Available online

http://www.phcogj.com/v13/i5

Copyright

(C) 2021 Phcogj.Com. This is an openaccess article distributed under the terms of the Creative Commons Attribution 4.0 International license.

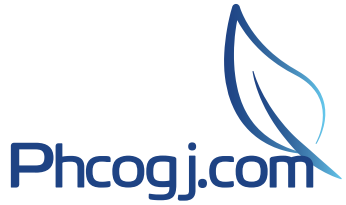

\begin{abstract}
Background: Hypothyroidism is a common side effect found in patients with multidrug-resistant tuberculosis taking ethionamide. The mechanism of ethionamide-induced hypothyroidism is potentially caused by the structure of ethionamide compounds chemically similar to thioamide, such as propylthiouraci (C7H8N2S), which inhibits thyroid hormone synthesis. However, hypothyroidism is caused not only by a lack of production but also by signaling alteration. Thyroid hormone action is mediated by thyroid hormone receptors (TRs), members of the nuclear receptor superfamily that regulate their target genes. Unfortunately, there are limited studies on the potential interaction of ethionamide with TRs. Objective: In the present study, we want to elaborate on the potential interaction of ethionamide with TRs which might alter the thyroid hormone genomic regulation. Methods: Molecular docking studies were used to evaluate the potential interaction between ethionamide with TR $\alpha$ and TR $\beta$. Results: The molecular docking results on TR $\alpha$ showed more than one hydrogen bond-steric interaction formed from the ethionamide-amino acid residue interaction. Ethionamide-TR $\beta$ interaction showed more than one steric interaction, but the hydrogen bonds are not visualized. The docking score between ethionamide and TRa is $-7.373 \mathrm{kcal} /$ $\mathrm{mol}$ and higher than its interaction with TR $\beta$. Conclusion: These findings indicate that ethionamide can interact with TR $\alpha$ and TR $\beta$. However, the ethionamide-TR $\alpha$ interaction is stronger than ethionamide-TR $\beta$ interaction. Our study reports a novel mechanism of action of ethionamide-induced hypothyroidism. Key words: Ethionamide, Hypothyroidism, Molecular docking, TR $\alpha$, TR $\beta$
\end{abstract}

\section{INTRODUCTION}

Ethionamide (2-ethyl pyridine-4-carbothioamide, $\left.\mathrm{C}_{8} \mathrm{H}_{10} \mathrm{~N}_{2} \mathrm{~S}, \mathrm{ETH}\right)$ is a nicotinamide derivative that has a molecular structure of ETH. ETH belongs to the anti-tuberculosis agent class that is used as a second-line treatment regimen in patients with multidrug-resistant tuberculosis (MDR-TB). ${ }^{1}$ ETH has several adverse effects. ${ }^{2-4}$ The most common adverse effect and concern is that ETH can cause mild to moderate hypothyroidism..$^{5-11}$ On the basis of studies conducted in several countries, there are data on patients with hypothyroidism due to ETH in Egypt (39.5\%), Botswana (16.2\%), Russia (17.2\%), Peru (10\%), and Lesotho (69\%)..$^{5-8}$ Hypothyroidism due to ETH is common in children and people with human immunodeficiency virus (HIV). ${ }^{9-11}$

Thyroid hormones (THs) (3,5,3'-triiodo-Lthyronine or $\mathrm{T}_{3} ; 3,5,3^{\prime}, 5^{\prime}$-tetraiodo-L-thyronine or thyroxine or $\mathrm{T}_{4}$ ) signaling plays critical roles in regulating mammalian development and metabolism, including the development of the central nervous system in infants, skeletal growth in children, and the normal function of multiple organ systems in adults. ${ }^{12,13} \mathrm{TH}$ regulation is under negative feedback regulation by the hypothalamicpituitary-thyroid axis. Thyroid-stimulating hormone (TSH) from the anterior pituitary binds to the TSH receptor (TSHR) located on the basolateral membrane of thyroid follicular epithelial cells and then promotes the production of the THs, $\mathrm{T}_{3}$ and $\mathrm{T}_{4}{ }^{12}$ TSHR is a glycoprotein hormone receptor, a subfamily of class A G-proteincoupled receptors (GPCRs). GPCRs are essential for signal transducers and regulators. ${ }^{14}$ Direct
TSHR activation and G proteins' coupling leads to a cascade of complex intracellular events resulting in thyrocyte growth and hormone production. ${ }^{15}$ TSH is a marker for thyroid function, and a normal TSH level indicates the proper thyroid function. On the basis of the definition of hypothyroidism used by Satti et al., hypothyroidism is defined using the cutoff TSH level of $>10 \mathrm{mIU} / \mathrm{mL}^{6}$

TH's action is mediated by TH receptors (TRs) that are members of the nuclear receptor superfamily that act as ligand-dependent transcription factors, which bind to a specific DNA sequence called the TH response element (TRE) as a homodimer or as a TR-heterodimer with the retinoid $\mathrm{X}$ receptor (RXR). Two different genes express two different TR subtypes, TR $\alpha$ and TR $\beta .{ }^{16}$ TR $\alpha$ regulates heart rate and contractility, and TR $\beta$ controls cholesterol metabolism and TSH production. ${ }^{17}$ In the absence of ligand $\left(\mathrm{T}_{3}\right)$, $\mathrm{TR}$ is associated with co-repressor proteins, and then gene transcription is inhibited. However, in the presence of $\mathrm{T}_{3}$, the co-repressors are replaced by coactivator complexes, including the steroid receptor coactivators (SRC)-1, SRC2 , and SRC-3 to activate transcription. TH exerts its actions through genomic and nongenomic pathways. ${ }^{18,19}$ If hypothyroidism occurs, it interferes with cell metabolism by disrupting the signaling and regulation of the expression of various genes in the nucleus, cytoplasm, and mitochondria, resulting in mitochondrial dysfunction and decreased cell viability. Hypothyroidism could affect all tissues and organs. It can cause muscle, skin, pulmonary, cardiac, gastrointestinal, renal, and neurological dysfunctions. ${ }^{12}$

Cite this article: Lesmana R, Shidqi ER, Goenawan H, Setiawan I, Gondokesumo ME, Suhud $F$, et al. The Potential Interaction of Ethionamide-Thyroid Hormone Receptor Induces Hypothyroidism. Pharmacogn J. 2021;13(5): 1174-1179. 
Currently, the known mechanism of ETH-induced hypothyroidism occurs because ETH compounds chemically similar to thioamide, such as propylthiouracil. ${ }^{20}$ These drugs can cause hypothyroidism by inhibiting TH synthesis through a mechanism of iodine organification inhibition. ${ }^{20-22}$ However, it is unknown whether the genomic pathway also contributes to ETH-induced hypothyroidism. Molecular docking is a computational procedure that attempts to efficiently predict the noncovalent binding between a receptor (protein) and a ligand. ${ }^{23}$ Molecular docking algorithms execute quantitative predictions of binding energetics, providing rankings of docked compounds based on ligandreceptor complex binding affinity. ${ }^{24}$ Thus, molecular docking will show potential ETH-TR $\alpha$ and ETH-TR $\beta$ interactions. Our data will reveal another possible mechanism of ETH-induced hypothyroidism.

\section{MATERIALS AND METHODS}

All the in silico calculations were performed using a Lenovo IdeaPad 3 15-inch with an Intel ${ }^{\circ}$ Core $^{\mathrm{ma}}$ i5-1035G1 processor and a memory of 8 GB DDR4 $2667 \mathrm{MHz}$ (4 GB Soldered + 4 GB DIMM) and running on a Windows 10 Home 64 operating system.

\section{Ligand preparation}

The molecular structure of ETH (PubChem CID 2761171) was downloaded from PubChem (https://pubchem.ncbi.nlm.nih.gov/) in the structure data file format. The ETH structure was then opened with Chem3D software to minimize energy and saved in protein data bank (PDB) format. Then, the three-dimensional (3D) ETH structure was optimized using AutoDockTools 1.5.7 software (http://autodock. scripps.edu/resources/adt). Optimization is done by adding hydrogen atoms, removing water molecules, and partial charging of Gasteiger charges. We then searched for geometric conformation based on the torsion of ETH and got the geometric conformation with the lowest energy. The input file was generated in the PDBQT format.

\section{Receptor preparation}

The crystal structures of the TRa (PDB ID: 4LNX) and TR $\beta$ (PDB ID: 3JZC, 1Q4X) were downloaded from the PDB (http://www.rcsb.org/ $\mathrm{pdb} /$ home/home.do) in PDB format. The 3D structure files of the TRa and TR $\beta$ crystal structures were opened and modified with Discovery Studio Visualizer software, version 4.0 (BIOVIA/Accelrys Inc., San Diego, CA, USA). The water molecules and other substructures (bound or ligand molecules) were removed from the coordinate file before docking. The water molecules were deleted to simplify the energy calculation for the simulation. The results (without ligands) were saved in PDB format. The ETH structure's PDB format was opened with AutoDockTools 1.5.7 software and was followed by adding Kollman charges and polar hydrogens. Then, the input file was generated in the PDBQT format.

\section{Parameter grid and docking simulation}

Molecular docking was performed to identify and calculate the receptor-ligand interactions. The unliganded TR $\alpha$ and $\operatorname{TR} \beta$ were used for individual docking with ETH. AutoGrid was used for the preparation of the grid map using a grid box with a docking box. The coordinates for docking were determined through a grid box $60 \times 60 \times 60 \AA$ for TR $\alpha$ and $60 \times 60 \times 60 \AA$ for TR $\beta$. The box spacing was $0.375 \AA$. Finally, AutoDock was run using a maximum number of 10,000 retries and 27,000 generations. The docking possibilities were calculated using a genetic algorithm with local search. For each ETH, the stimulation was composed of 1000 docking runs using the standard AutoDock parameters. Molecular docking was done using AutoDock 4 and AutoDock Vina as docking software (Trott and Olson, 2010) using a blind docking strategy to include the entire possible binding site for the ligands. The binding affinity was expressed as the binding free energy $(\mathrm{kcal} / \mathrm{mol})$.

\section{Data analysis from molecular docking}

The value of free binding energy can be evaluated by opening the docking "dock.dlg" file using Notepad++ (downloaded from https:// notepad-plus-plus.org/download/v7.5.8.html). We then observed the histogram for each cluster to find the lowest bond energy affinity for each docking result-the lower the energy, the stronger the interaction. The conformation of molecular docking results was visualized using AutoDockTools. Visualization of the bonds that occur between the ligands of each macromolecule is done using the PyMOL Visualization Tool (downloaded from https://pymol.org/2/) and Molegro 5.5 software. The best post-docking compound structure must fulfill the following requirements: it has the lowest energy, and the molecules are in the same active site as the native ligand, which can be visually observed in the protein structure. Observations of ligand-protein interactions, including hydrogen bonding, steric (van der Waals) interactions, and electrostatic interactions, were performed for the pose with the highest score.

\section{RESULTS AND DISCUSSION}

\section{Method validation}

Molecular docking is performed to study the binding environment for the ETH interacting within the receptors TR $\alpha$ and TR $\beta$. The molecular docking results reveal the complex ligand-receptor interactions and active conformations. The validation of docking was conducted by redocking the native ligand of the receptor into its active site. Native ligands are built-in ligands that bind to the target protein in the PDB file when downloaded. The crystal structures used in our docking studies are summarized in Table 1. Three molecules (GC-24, TRIAC, and T4) with known dissociation constants (Ki values) for TRa and $\mathrm{TR} \beta$ were docked to the receptor proteins. After redocking, the native ligand structure conformation resulted from the redocking overlap with the native ligand structure conformation in PDB. Validation evaluation parameters are root mean square deviation (RMSD) and visual position. RMSD is the difference between the predicted value and the observed experimental value and is a measure of the precision value with consistent results for repeated experiments. The RMSD evaluation was conducted by determining the RMSD value of the ligands based on the following ranges: RMSD $\leq 1.0 \AA$ for good or true conformations, $1.0 \AA<$ RMSD $\leq 2.0 \AA$ for near true conformations, $2.0 \AA<\mathrm{RMSD} \leq 3.0 \AA$ for conformations with error, and RMSD $>3.0 \AA$ for poor conformation (Bajda et al., 2014). Criteria of acceptance were set with the value of RMSD below 2.0 $\AA$. The RMSD calculation results show that the RMSD of TRa (PDB ID: 4LNX) is $1.918 \AA$, TR $\beta$ (PDB ID: 3JZC) is $0.814 \AA$, and TR $\beta$ (PDB ID: 1Q4X) is $0.755 \AA$. All crystal structures used in our docking studies have RMSD below $2.0 \AA$. We proved that our docking method is appropriate to investigate the ETHreceptor protein interaction with this validation.

\section{Docking to the TRs}

In this study, we evaluated ETH-TR $\alpha$ and ETH-TR $\beta$ interactions. Previous studies suggested that ETH may contribute to thyroid dysfunction because ETH compounds are chemically similar in structure to thioamides, such as propylthiouracil and methimazole $\left(\mathrm{C}_{4} \mathrm{H}_{6} \mathrm{~N}_{2} \mathrm{~S}\right) .{ }^{20} \mathrm{ETH}$ acts as a competitive inhibitor of thyroid peroxide, which causes inhibition of iodine uptake into thyroid cells, thereby

Table 1: Crystal structures used in our docking studies and their RMSD.

\begin{tabular}{|c|c|c|c|}
\hline TR isoform & Ligand & PDB-ID & RMSD (Å) \\
\hline a & $\mathrm{T} 4$ & 4LNX (Souza et al. 2014) & 1.918 \\
\hline \multirow{2}{*}{$\beta$} & GC-24 & 1Q4X (Borngraeber et al. 2003) & 0.755 \\
\hline & TRIAC & 3JZC (Martinez et al. 2009) & 0.814 \\
\hline
\end{tabular}


inhibiting the formation of iodine. The inhibition of $\mathrm{TH}$ synthesis decreases $\mathrm{T}_{3}$ and $\mathrm{T}_{4}$ in the circulation. ${ }^{20-22}$ However, hypothyroidism is caused not only by lack of $\mathrm{TH}$ production but also by signaling alteration. However, the molecular mechanisms of how ETH causes hypothyroidism remain unknown, and the literature regarding the specific effects of ETH on TR is lacking.

After validating the binding pocket by redocking the original ligand to the receptor to its active site, the ETH compound is bound to the TR $\alpha$ and TR $\beta$ binding pockets. To investigate ETH's binding modes to the TR-ligand-binding domain (LBD), we generated in silico binding models by molecular docking using AutoDocks Vina (Trott and Olson, 2010). The 3D docking configuration in the form of ETH-receptor interactions are shown in Figure 1.

The molecular docking results on TRa showed that two hydrogen bonds formed from the ETH compound molecule interaction with the amino acid residues Arg 228 and Met 259 in the 4LNX receptor active site (Figure 2A). Hydroxy groups form hydrogen bonds at the center of the structure, amide groups (peptide bonds), or other groups that can be hydrogen bond donors or acceptors. In the hydrogen bonds formed with the Arg 228 and Met 259 residues, ETH received proton from the two residues. The ETH-TRa protein interaction is also through steric interactions with the amino acid residues of Arg 266 (Figure 2A). Steric effects are nonbonding interactions that influence the shape (conformation) and reactivity of ions and molecules. The interaction through hydrogen bonds and steric interactions at the active site cause the docking score (rerank score) between ETH and TRa to have the highest value, which is $-7,373 \mathrm{kcal} / \mathrm{mol}$ (Table 2).

A.

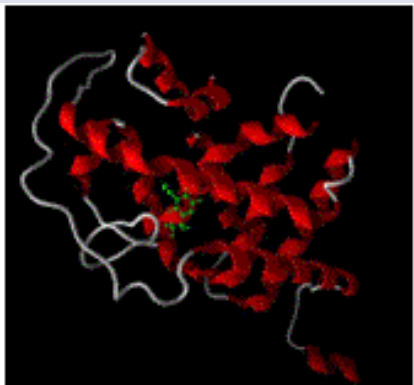

B.

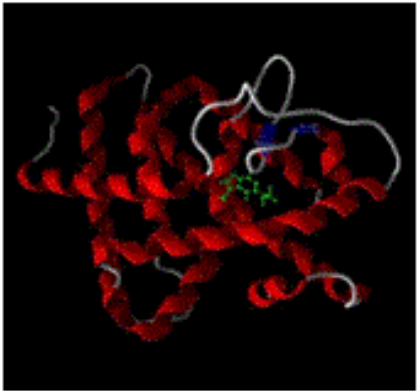

c.

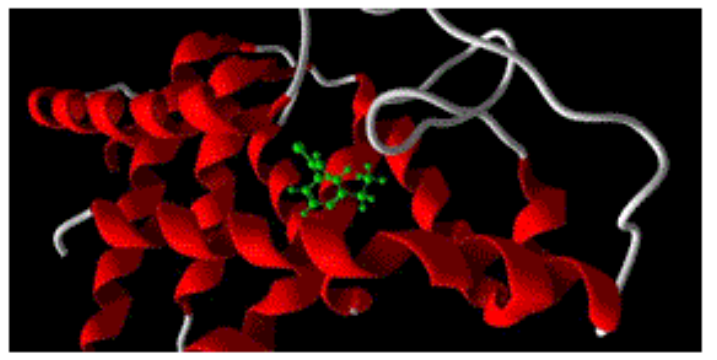

Figure 1: Ethionamide can bind to the active site of TR $\alpha$ and TR $\beta$. Threedimensional (3D) docking conformation in the form of interactions between ethionamide (green) and receptors (A) 4LNX, (B) 1Q4X, and (C) 3JZC.
A.

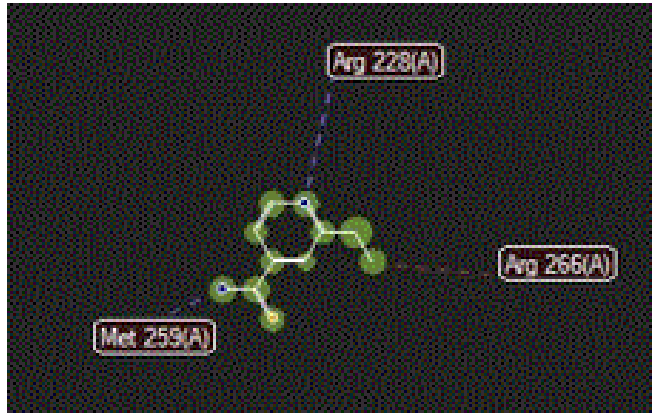

B.

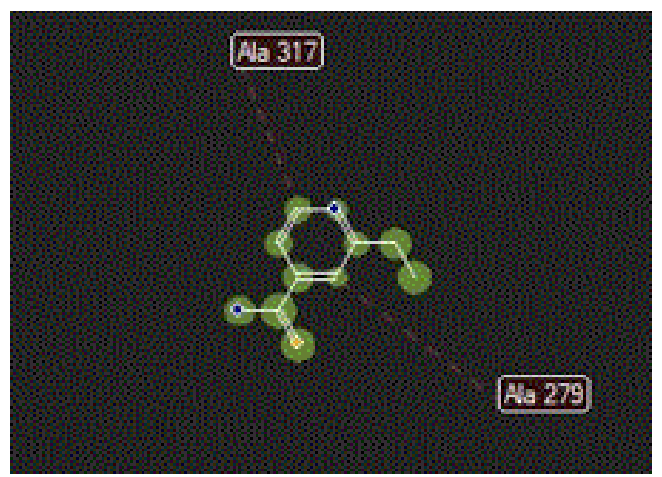

C.

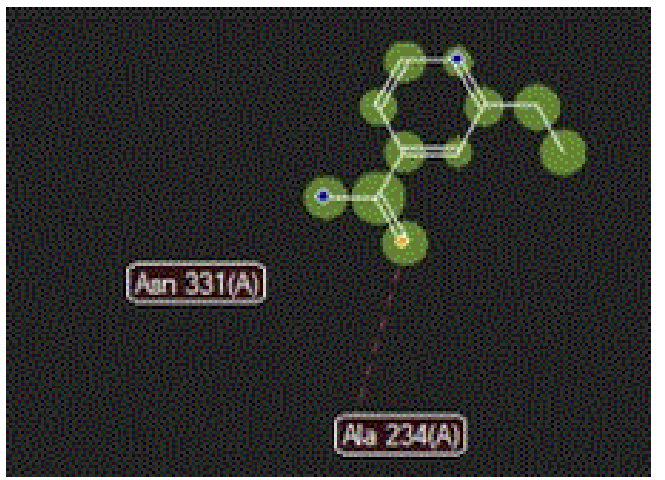

Figure 2: The interaction between ethionamide with TR $\alpha$ and TR $\beta$. Two-dimensional (2D) structure of hydrogen bonding interactions (blue dashed line) and steric interactions (red dashed line) between ethionamide compound molecules and amino acids in the active site TRs. (A) In TRa (4LNX), ethionamide forms two hydrogen bonds with the amino acids Arg 228, Met 259, and shows one steric interaction with Arg 266. (B) in TRB (1Q4X) shows two steric bonds with Ala 317, Ala 279. Whereas (C) shows two steric bonds between TRB ( $3 \mathrm{JZC}$ ) and ethionamide in amino acids Ala 234, Asn 331. Images obtained from the Molegro 5.5 program.

Table 2: Molecular docking result.

\begin{tabular}{|c|c|c|c|c|c|}
\hline Compound & $\begin{array}{l}\text { TR } \\
\text { Isoform }\end{array}$ & $\begin{array}{l}\text { Protein } \\
\text { (PDB ID) }\end{array}$ & $\begin{array}{l}\Delta \mathrm{G}(\mathrm{kcal} / \\
\mathrm{mol})\end{array}$ & $\begin{array}{l}\text { Hydrogen Bond } \\
\text { Interaction }\end{array}$ & $\begin{array}{l}\text { Steric } \\
\text { Interaction }\end{array}$ \\
\hline \multirow{3}{*}{ Ethionamide } & $a$ & $4 \mathrm{LNX}$ & -7.373 & Arg 228, Met 259 & Arg 266 \\
\hline & \multirow{2}{*}{$\beta$} & 1Q4X & -7.283 & - & $\begin{array}{l}\text { Ala } 317, \\
\text { Ala } 279\end{array}$ \\
\hline & & $3 \mathrm{JZC}$ & -7.243 & - & $\begin{array}{l}\text { Asn } 331, \\
\text { Ala } 234\end{array}$ \\
\hline
\end{tabular}

The molecular docking of TR $\beta$ showed that there is a steric interaction between the ETH compound molecule and the 1Q4X receptor on the amino acid residues Ala 317 and Ala 279 (Figure 2B). Meanwhile, the steric interaction between ETH compound molecules and the 3JZC receptor is found in the amino acid residues Asn 331 and Ala 234 (Figure 2C). Hydrogen bonds were not found. The ETH's affinity 
bonds with the two TR $\beta$ receptors, 1Q4X and 3JZC, were $-7,283$ and $-7,243 \mathrm{kcal} / \mathrm{mol}$, respectively.

Using in silico analysis, we found that ETH may directly interact with the TR-LBD. Like other nuclear receptors, the TR-LBDs have a core binding site for $\mathrm{T}_{3}$, where the ligand is buried. The binding of $\mathrm{THs}$ can change the conformation of TRs (Souza et al., 2014; Moras et al., 2015). We showed a potential mechanism of action of ETH-induced hypothyroidism by direct binding of ETH to TRs (Figure 1). Our data showed that the docking score between ETH and TR $\alpha$ has a higher value than its interaction with TR $\beta$. The higher the docking score, the lower the ligand-protein interaction energy and the higher the biological activity.

The TH nuclear receptor consists of several domain structures. The differences in the domain structure characteristics lead to the formation of several TR $\alpha$ and TR $\beta$ isoforms. TR $\alpha$ and TR $\beta$ isoforms have different locations and functions. $\mathrm{TR} \mathrm{a}_{1}$ has the highest expression in the bone, gastrointestinal tract, cardiac and skeletal muscle, and central nervous system. $\mathrm{TR \alpha _{2 }}$ and $\mathrm{TR} \alpha_{3}$ are predominant in the brain, kidney, testis, brown adipose tissue, and skeletal muscle. Although a dominantnegative function has been attributed to mammalian $\mathrm{TRa}$, which is widely co-expressed with $\mathrm{TR} \alpha_{1}, \mathrm{TR} \alpha_{2}$ modulates thyrotropin-releasing hormone gene expression in the hypothalamus. ${ }^{25}$ Thus, ETH-TRa interaction may affect these organs' activity and metabolic function. However, ETH-TR $\beta$ interaction may affect the organs' activity and metabolic function that have these receptors. TR $\beta_{1}$ is most abundant in the liver, kidney, and inner ear. $\operatorname{TR} \beta_{2}$ is predominant in the hypothalamus, pituitary, cochlea, and retina, and $\mathrm{TR} \beta_{4}$ is a relatively high expression in the brain and kidney. ${ }^{26-28}$

ETH binding to TR-LBD may also induce conformational changes in the structure of TRs and then regulate their target genes in specific cell targets. A multifaceted cascade of events results in the binding of TRs to TREs and culminates in the modulation of target gene expression in response to $\mathrm{TH}^{29}$ Previous studies conducted by Lesmana et al. showed that ETH could significantly up-regulate the expression of thyroid receptor and iodothyronine deiodinase in the soleus and cardiac muscle cells. ${ }^{30}$ Deiodinase is essential for the biological activity of TH. The up-regulation of TR and iodothyronine deiodinase gene expression may indicate a compensation for hypothyroidism in the muscle environment. The hormone receptor can activate or repress gene transcription depending on the promoter context and ligandbinding status. ${ }^{19}$ In the absence of $\mathrm{T}_{3}$, the unliganded TR undergoes conformational changes and recruits co-repressor complexes that include the nuclear co-repressor, the silencing mediator for RXR and $\mathrm{TR}$, and histone deacetylases. ${ }^{29,31}$ This co-repressor complex integrates several enzymatic activities that modify chromatin towards a closed structure, resulting in a transcriptionally silent state. ${ }^{18}$ However, the presence of $\mathrm{T}_{3}$ that binds to TR resulted in a new set of activator proteins that bind to the receptor. These activator proteins include the SRC-1, nuclear coactivator 1 , the transcriptional intermediary factor 2, the cAMP-response element-binding protein-binding protein (CBP), also known as p300, the p300/CBP-associated factor, and histone acetyltransferase. Activator protein activity leads to changes in chromatin structure and the subsequent transcription of the target gene. $^{29,31}$

Molecular docking results showed a potential ETH-thyroid receptor interaction. These findings indicate that ETH may alter TH signaling through TR signaling pathways that may contribute to causing hypothyroidism in patients with MDR-TB. However, further studies and research are needed to test the interaction and determine the next steps in improving the outcome of MDR-TB treatment.

\section{CONCLUSIONS}

On the basis of the results of molecular docking, ETH can interact with TR $\alpha$ and TR $\beta$. However, based on the value of free energy binding and hydrogen bonds, ETH-TR $\alpha$ interaction is better than ETH-TR $\beta$ interaction. We proposed a novel mechanism of action of ETHinduced hypothyroidism by direct binding of the ETH to TRs.

\section{ACKNOWLEDGEMENT}

The authors would like to thank Ardo Sanjaya for proofreading the article. This article was funded by PDUPT research grant from Indonesia Ministry of Research to Ronny Lesmana (2020).

\section{REFERENCES}

1. PubChem [database on the Internet]. Bethesda (MD): National Library of Medicine (US), National Center for Biotechnology Information; 2004-. PubChem Compound Summary for CID 2761171, Ethionamide; [cited 2020 June 25].

2. Available from: https://pubchem.ncbi.nlm.nih.gov/compound/ Ethionamide

3. World Health Organization. WHO Consolidated Guidelines on DrugResistant Tuberculosis Treatment. Geneva, Switzerland. 2019.

4. Katzung BG, Masters SB, Trevor AJ. Basic \& Clinical Pharmacology New York: McGraw-Hill; 2012. p. 843-844.

5. Ramachandran G, Swaminathan S. Safety and Tolerability Profile of Second-Line Anti-Tuberculosis Medications. Drug Safety. 2015;38(3), 253-269.

6. Tola HH, Holakouie-Naieni K, Lejisa T, et al. Is hypothyroidism rare in multidrug resistance tuberculosis patients on treatment? A systematic review and meta-analysis. PLoS One. 2019;14(6):e0218487.

7. Satti H, Mafukidze A, Jooste PL, McLaughlin MM, Farmer PE, Seung KJ. High rate of hypothyroidism among patients treated for multidrug-resistant tuberculosis in Lesotho. Int J Tuberc Lung Dis. 2012;16(4):468-72

8. Munivenkatappa S, Anil S, Naik B, Volkmann T, Sagili KD, Akshatha JS, Buggi S, Sharada MA, Kulkarni S, Chadha VK, Moonan PK. Drug-induced hypothyroidism during anti-tuberculosis treatment of multidrug-resistant tuberculosis: notes from the field. Journal of tuberculosis research. 2016;4(3):105

9. Modongo C, Zetola NM. Prevalence of hypothyroidism among MDRTB patients in Botswana. Int J Tuberc Lung Dis. 2012;16(11):1561.

10. Brust JC, Shah NS, Van Der Merwe TL, Bamber S, Ning Y, Heo M, Moll AP, Loveday M, Lalloo UG, Friedland GH, Gandhi NR. Adverse events in an integrated, home-based treatment program for MDRTB and HIV in KwaZulu-Natal, South Africa. Journal of acquired immune deficiency syndromes (1999). 2013;62(4):436.

11. Andries $A$, Isaakidis $P$, Das $M$, et al. High rate of hypothyroidism in multidrug-resistant tuberculosis patients co-infected with HIV in Mumbai, India. PLoS One. 2013;8(10):e78313.

12. Thee S, Zöllner EW, Willemse M, Hesseling AC, Magdorf K, Schaaf HS. Abnormal thyroid function tests in children on ethionamide treatment. Int J Tuberc Lung Dis. 2011;15(9):1191-i.

13. Molina PE, Ashman R. Endocrine Physiology. New York: McGrawHill; 2013. p.88-90

14. Stathatos N. Thyroid Physiology. Med Clin North Am. 2012;96(2):165-173.

15. Hilger D, Masureel M, Kobilka BK. Structure and dynamics of GPCR signaling complexes. Nat Struct Mol Biol. 2018;25(1):4-12.

16. Davies TF, Latif R. Targeting the thyroid-stimulating hormone receptor with small molecule ligands and antibodies. Expert Opin Ther Targets. 2015;19(6):835-847. 
17. Mullur R, Liu YY, Brent GA. Thyroid hormone regulation of metabolism. Physiol Rev. 2014;94(2):355-382.

18. Korta P, Pocheć E. Glycosylation of thyroid-stimulating hormone receptor. Endokrynol Pol. 2019;70(1):86-100.

19. Weitzel JM, Iwen KA. Coordination of mitochondrial biogenesis by thyroid hormone. Mol Cell Endocrinol. 2011;342(1-2), 1-7.

20. Cioffi F, Senese R, Lanni A, Goglia F. Thyroid hormones and mitochondria: With a brief look at derivatives and analogues. Mol Cell Endocrinol. 2013;379(1-2), 51-61

21. Choi J, Park SJ, Jee JG. Analogues of ethionamide, a drug used for multidrug-resistant tuberculosis, exhibit potent inhibition of tyrosinase. European Journal of Medicinal Chemistry. 2015:106,157-166

22. Manna D, Roy G, Mugesh G. Antithyroid drugs and their analogues: synthesis, structure, and mechanism of action. Acc Chem Res. 2013;46(11):2706-2715

23. Tousson E, Ibrahim W, Arafa N, Akela MA. Monoamine concentrations changes in the PTU-induced hypothyroid rat brain and the ameliorating role of folic acid. Human \& experimental toxicology. 2012;31(3):282-9.

24. Trott O, Olson AJ. AutoDock Vina: improving the speed and accuracy of docking with a new scoring function, efficient optimization, and multithreading. J Comput Chem. 2010;31(2):455-461.
25. de Ruyck J, Brysbaert G, Blossey R, Lensink MF. Molecular docking as a popular tool in drug design, an insilico travel. Adv Appl Bioinform Chem. 2016;9:1-11

26. Guissouma H, Ghaddab-Zroud R, Seugnet I, Decherf S, Demeneix B, Clerget-Froidevaux MS. TR a2 exerts dominant negative effects on hypothalamic Trh transcription in vivo. PLoS One. 2014;9:e95064

27. Flamant F, Gauthier K. Thyroid hormone receptors: the challenge of elucidating isotype-specific functions and cell-specific response. Biochim Biophys Acta. 2013;1830:3900-3907

28. Hahm JB, Privalsky ML. Research resource: identification of novel coregulators specific for thyroid hormone receptor- $\beta 2$. Mol Endocrinol. 2013:27:840-859.

29. Vella KR, Hollenberg AN. The actions of thyroid hormone signaling in the nucleus. Mol Cell Endocrinol. 2017:458:127-135

30. Anyetei-Anum CS, Roggero VR, Allison LA. Thyroid hormone receptor localization in target tissues. J Endocrinol. 2018;237(1):R19-R34.

31. Lesmana R, Setiawan S, Efza F, Pratiwi YS, lqbal GM, Goenawan H, Sylviana N, Supratman U. Ethionamide Alters Thyroid Receptor Gene Expression in Rats' Muscle. The Indonesian Biomedical Journal. 2020;12(3):220-6

32. Giammanco M, Di Liegro CM, Schiera G, Di Liegro I. Genomic and Non-Genomic Mechanisms of Action of Thyroid Hormones and Their Catabolite 3,5-Diiodo-L-Thyronine in Mammals. Int J Mol Sci. 2020:21(11):4140

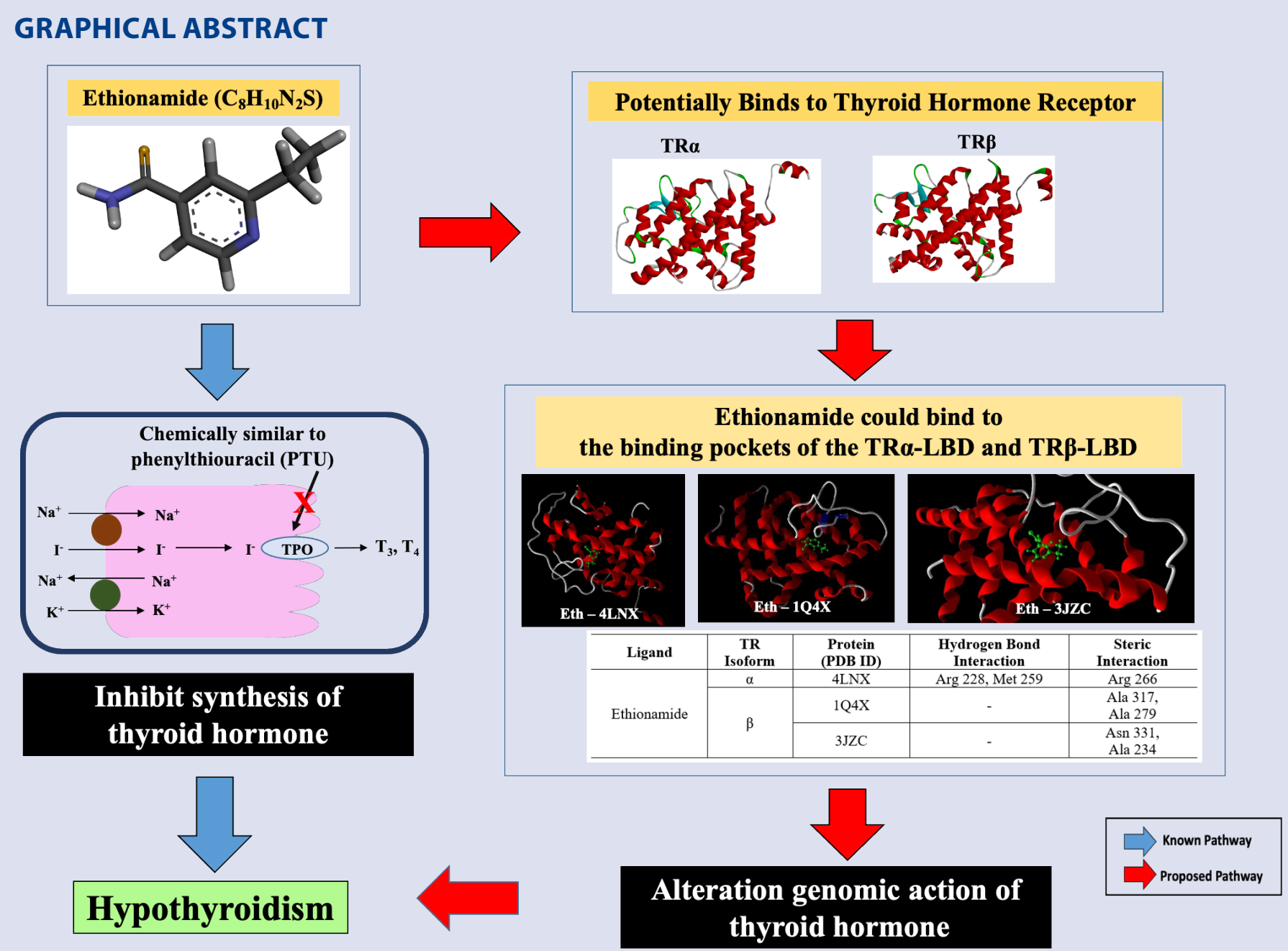




\section{ABOUT AUTHORS}
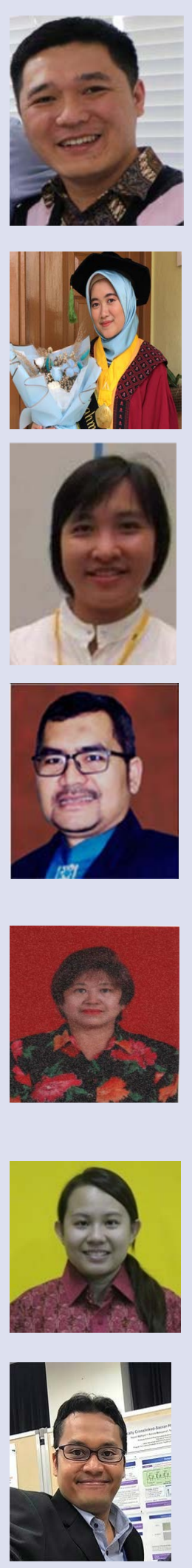

Ronny Lesmana, had graduated as medical doctor and also finished his master level from Faculty of Medicine at Universitas Padjadjaran, further he continued his Doctorate level at Gunma University. Since 2006 until now, he has been working as a lecturer and associate professor at the Faculty of Medicine, University of Padjadjaran. His interest is exercise physiology and endocrinology. Latest publication is about Hippo pathway effectors YAP and TAZ and their association with skeletal muscle ageing, in which we had explored the modulation of YAP/TAZ or the Hippo pathway in general may offer potential new strategies for the prevention or treatment of ageing.

Firyali Rahmani Shidqi is a fourth-year medical student at the Faculty of Medicine, Universitas Padjadjaran, Bandung, Indonesia. She received a bachelor's degree in the Medical Program, Faculty of Medicine, Universitas Padjadjaran. Currently, Her interest is study and research related with internal medicine as well as physiology and biomedical sciences.

Hanna Goenawan, was graduated from Faculty of Medicine, Universitas Padjadjaran and continue to pursue PhD degree at Dept of Neurophysiology, Gunma University Graduate School of Medicine. Currently, she has been working as assistant professor in Physiology Division, Department of Biomedical Sciences, Faculty of Medicine, Universitas Padjadjaran. Her research theme is focused on molecular physiology and exercise physiology on body organ system.

Iwan Setiawan, had graduated as medical doctor from Faculty of Medicine at Universitas Padjadjaran, further he continued his Doctorate level at Tubingen University. Currently, he has been working as associate professor at the Faculty of Medicine, University of Padjadjaran. His interest is exercise physiology and endocrinology. Latest publication is about Hippo pathway effectors YAP and TAZ and their association with skeletal muscle ageing, in which we had explored the modulation of YAP/TAZ or the Hippo pathway in general may offer potential new strategies for the prevention or treatment of ageing.

Farida Suhud, had graduated from the Faculty of Pharmacy, Airlangga University, further study S2 and S3 at the same place. Since 1989 until now, she has worked as a lecturer at the Faculty of Pharmacy, University of Surabaya. Her field of study so far is Medicinal Chemistry. The design of urea derivative drugs that work as anticancer is the first choice taken to complete the doctoral dissertation. The drug design is aimed at the discovery of new anticancer drugs that work selectively, effectively and safely. It is hoped that the research conducted can make a valuable contribution to society in the future, considering that cancer cases are increasing from year to year.

Marisca Evalina Gondokesumo had finished studied at Biomedical Sciences Doctoral Program Faculty of Medicine, Brawijaya University, Malang city, East Java, Indonesia. She is working as a lecturer in Faculty of Pharmacy, University of Surabaya (UBAYA) East Java, Indonesia. Her latest publication was "Microstructural characterization of the Garcinia mangostana fruit at Different Maturity Level". Her latest research was about Antioxidant Activity Analysis of Six Different Maturity Levels of Mangosteen Rind Extract (Garcinia mangostana Linn.) using Electron spin resonance (ESR).

Dr. Nasrul Wathoni obtained his Doctoral degree in Pharmaceutical Sciences from Kumamoto University, Japan. Currently he is working as Associate Professor at Department of Physical Pharmaceutic, Faculty of Pharmacy Universitas Padjadjaran, Bandung, Indonesia. His main area of interest related to Dermal and Transdermal Drug Delivery System. His area of expertise includes hydrogel film and polymeric nanoparticle based natural polysaccharides.

Cite this article: Lesmana R, Shidqi ER, Goenawan H, Setiawan I, Gondokesumo ME, Suhud F, et al. The Potential Interaction of Ethionamide-Thyroid Hormone Receptor Induces Hypothyroidism. Pharmacogn J. 2021;13(5): 1174-1179. 